\title{
A microdialysis technique for continuous subcutaneous glucose monitoring in diabetic patients (part 1)
}

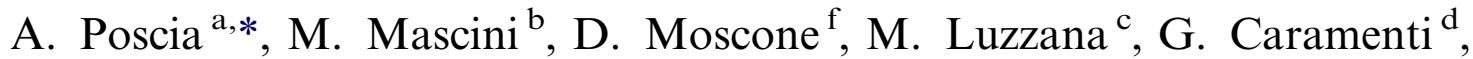

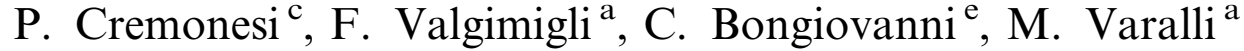 \\ ${ }^{a}$ Research and Development Department, A. Menarini Industrie Farmaceutiche Riunite S.r.l., Via Sette Santi, Florence 3-50131, Italy \\ ${ }^{\mathrm{b}}$ Dipartimento di Chimica Università di Firenze, Polo Santifico, Viadella Lastruccia, 3, Sesto Fiorentino (FI) 50019, Italy \\ ${ }^{\mathrm{c}}$ Dipartimento di Scienze e Tecnologie Biomediche; Università di Milano Via Fratelli Cervi, 93-20090 Segrate, Milan, Italy \\ ${ }^{\mathrm{d}}$ I.T.B. Istituto di Tecnologie Biomediche, C.N.R. Via Fratelli Cervi, 93-20090 Segrate, Milan, Italy \\ e INFM e Dipartimento di Biologia; Università di ROMA 'Tor Vergata', Via della Ricerca Scientifica, 00133 Rome, Italy \\ ${ }^{\mathrm{f}}$ Dipartimento di Scienze e Tecnologie Chimiche, Università di Roma "Tor Vergata", Via della Ricerca Scientifica, 00133 Rome, Italy
}

Received 23 March 2001; accepted 19 August 2002

\begin{abstract}
The performances and the stability of a novel subcutaneous glucose monitoring system have been evaluated. GlucoDay ${ }^{\circledR}$ (A. Menarini I.F.R. S.r.l, Florence Italy) is a portable instrument provided with a micro-pump and a biosensor coupled to a microdialysis system capable of recording the subcutaneous glucose level every 3 min. Long and short term stability of the biosensor are discussed and the results of some critical in vitro and in vivo (on rabbits) experiments are reported. A linear response up to 30 $\mathrm{mM}$ has been found for in vivo glucose concentration. The sensitivity referred to blood glucose is better than $0.1 \mathrm{mM}$ and the zero current is typically below the equivalent of $0.1 \mathrm{mM}$. In the accuracy study a mean bias of $2.7 \mathrm{mg} / \mathrm{dl}$ and a correlation coefficient equal to 0.9697 have been found. At room temperature, an excellent membrane stability assures good performances up to 6 months from the first use.
\end{abstract}

(C) 2002 Elsevier Science B.V. All rights reserved.

Keywords: Biosensors; Continuous monitoring; Glucose; Microdialysis

\section{Introduction}

During the last decade many efforts especially in Europe have been done to develop chemical sensors for in vivo monitoring (Scheller et al., 1987). A successful Concerted Action sponsored by EEC on this subject has been carried on for almost 7 years (1989-1995) and the cooperative efforts of more than 100 researchers through Europe have been sustained.

A booklet on this Action and a summary of the findings was recently published (Alcock and Turner, 1996).

The problem of continuous monitoring of glucose was difficult to solve (Vadagama and Desai, 1991). After

\footnotetext{
* Corresponding author. Tel.: +39-055-5680-368; fax: +39-0555680-576.

E-mail address: aposcia@menarini.it (A. Poscia).
}

years of research, progress has finally being made toward inplantable continuous glucose monitors (Pfeiffer et al., 1995; Hurd et al., 1988; Kerner et al., 1993). Two different kinds of devices have been proposed: fully implantable and percutaneous (worn through the skin). The first kind (Wagner et al., 1998) includes electronics and battery, it is designed for longevity and implanted subcutaneously or in a blood vessel by physician. The percutaneous type (Thome-Duret et al., 1996) is needlelike or inserted through a needle and it is designed to operate for few days and to be replaced by the patient.

Some of the new devices, such as GlucoWatch biographer (Cygnus, Redwood City, CA) and Continuous Glucose Monitoring System (CGMS; MiniMed Inc., CA, USA), have been successfully tested in animals and, after clinical studies, have been approved by FDA.

GlucoWatch biographer (Satish et al., 1999; Rao et al., 1993; Pitzer et al., 2001) allows frequent, automatic 


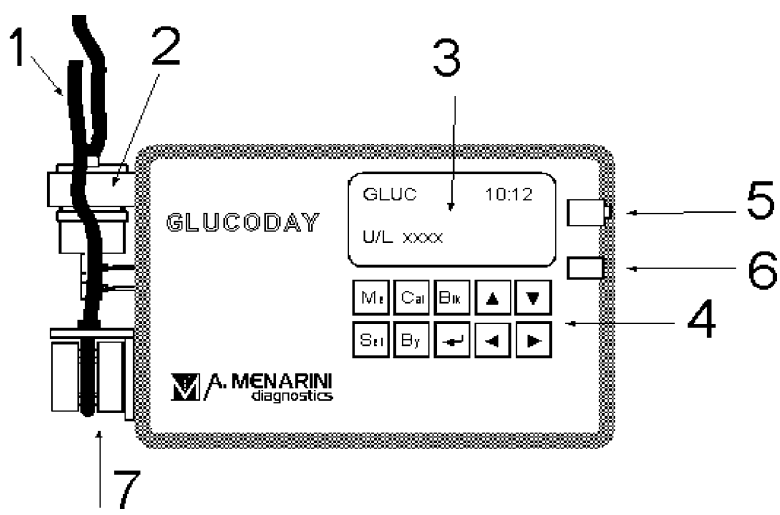

Fig. 1. (1) Fluidic line; (2) wall jet flow cell; (3) display; (4) keyboard; (5) RS232 interface to PC; (6) $12 \mathrm{~V}$ connector; (7) microperistaltic pump; (8) battery compartment.

and minimally invasive glucose monitoring. It performs three readings per hour for $12 \mathrm{~h}$ after calibration. It can be worn on the forearm like a watch and it extracts glucose through the skin by reverse iontophoresis.

The CGMS (Mastrototaro, 1999) consists of a glucose sensor, placed into the subcutaneous tissues (usually the abdomen) connected to a monitor worn by the patient. The system stores the subcutaneous glucose level every 5 $\min$.

These new approaches provide automatic glucose readings during the night, allowing more efficiently detection of episodes of hypoglycemia (but not below $50 \mathrm{mg} / \mathrm{dl}$ in case of CGMS, Minimed). However, they can not be used for all patients. For example, GlucoWatch detects trends in glucose levels only in adults.

In this paper, we report the development of a new wearable system based on the principle of the wall-jet cell. A glucose biosensor is coupled to a subcutaneously inserted microdialysis probe, obtained from hollow fibre, which is expressly produced and sterilised. It has already been discussed in the past the problems encountered with this approach (Moscone et al., 1992) and how to solve them with a special design of the hydrodynamic conditions of the flow system, the wall-jet cell with a glucose biosensor (Moscone and Mascini, 1993a,b,c). With this arrangement it was possible to measure glucose continuously up to $3 \mathrm{~h}$ both in animals and in humans. However, the apparatus was suitable only for laboratory studies (Moscone and Mascini, 1993a,b,c).

The apparatus used in this work weighs only $245 \mathrm{~g}$ (without battery) and includes a specially developed microperistaltic pump, a miniaturised wall-jet cell, which contains the glucose biosensor, an electronic circuit with a low power microprocessor, a $9 \mathrm{~V}$ battery supply and a fluidic pressure sensor. A disposable microdialysis probe and two reservoirs, one for the flowing buffer and the other for the waste, complete the device.

We demonstrate how this new device is able to overcome the problem of sensitivity variation of glucose biosensors reported in the past (Moscone et al., 1992; Aussedat et al., 2000).

\section{Materials and methods}

\subsection{The apparatus}

After preliminary experiments made on separate mechanical and electronic modules (pump, electronics controlling and data recording), engineered units have been developed and produced by A. Menarini I.F.R. (s.r.1. Firenze). Fig. 1 schematically presents the system, which possess the following characteristics:

- a programmable micropump with $15-100 \mu \mathrm{l} / \mathrm{min}$ flow rate;

- a fluidic line made of nylon in all the sections except in the peristaltic pump;

- a wall jet flow cell made of a platinum electrode and a three layers membrane system;

- a micro controller for pump speed programming, signal acquisition and data storage (12 bits resolution, 1800 data points);

- a 32 alphanumeric characters display and a keyboard;

- a RS232 interface at 1200 baud for downloading the data to PC;

- a $9 \mathrm{~V}$ battery for $48 \mathrm{~h}$ continuous data recording.

Two different flow rates can be used, a faster one for filling and/or washing the line, a slower one for the continuous feeding of the microdialysis probe.

Two plastic bags, one for the buffer solution and one for the wasted solutions, complete the apparatus, which for its dimension and weight can be contained in a pouch and can be comfortably worn as a belt.

\subsection{The glucose sensor}

A platinum anode (diameter $0.4 \mathrm{~mm}$ ) is melted into a glass cylinder, which is inserted into a silver tube that works as a cathode. The electrode is covered by three membranes (a cellulose acetate membrane, an enzymatic membrane and a polycarbonate membrane), held in place by a small piece of Teflon tube of suitable diameter. The cellulose acetate membrane removes the electrochemical interference from ascorbic and uric acid, allowing the passage of hydrogen peroxide only. Glucose oxidase (GOD; EC 1.1.3.4 from Aspergillus niger, $132 \mathrm{U} / \mathrm{mg}$ from Sigma) was immobilised on a nylon net according to the following procedure. A 5\% GOD solution $(5 \mu \mathrm{l})$, and a $0.25 \%$ glutaraldehyde solution (3 $\mu 1)$ were mixed together, spread onto a $1 \mathrm{~cm}^{2}$ nylon supporting net and left to dry (Moscone and Mascini, 1993a,b,c). 


\subsection{The microdialysis probe}

The probes were expressly assembled by the supplier using $2 \mathrm{~cm}$ of hollow fiber (regenerated cellulose $\varnothing$ i.d. $0.17 \mathrm{~mm}, \varnothing$ o.d. $0.20 \mathrm{~mm}$ and molecular weight cut-off (MWCO) of approximately 15000-20000 Da). The fiber was glued to two pieces of nylon tubing $(\varnothing$ i.d. $0.250 \mathrm{~mm}, \varnothing$ o.d. $0.750 \mathrm{~mm}$, from Portex, Ireland) through a cyanoacrylic glue (Sicomet 40, Sichel-Werke GmbFI, Hannover, Germany). To avoid the collapse of the membrane a pair of twisted tungsten wires $(0.05 \mathrm{~mm}$ diameter from Goodfellow, Cambridge, UK) were placed inside the fiber. For in vivo use the probes were sterilised with ethylene oxide gas.

\subsection{Chemicals}

The perfusion solution was prepared by adding $1 \mathrm{~g} / \mathrm{l}$ of a preservant (such as sodium benzoate) to a Dulbecco's physiological buffer $(\mathrm{NaCl} 136.9 \mathrm{mM}, \mathrm{KCl}$ $2.7 \mathrm{mM}, \mathrm{KH}_{2} \mathrm{PO}_{4} 1.5 \mathrm{mM}, \mathrm{Na}_{2} \mathrm{HPO}_{4} 8.1 \mathrm{mM}$, pH 7.4).

The glucose calibration solution $(0.5 \mathrm{mM})$ was prepared by dissolving $\beta-\mathrm{D}(+)$ glucose (Sigma) and $\mathrm{NaN}_{3}$ into a Dulbecco's physiological buffer. The solution was allowed to equilibrate overnight and suitably diluted. In order to prevent microbial growth, $0.1 \%$ of Kathon $\mathrm{CO}$ solution (Rotirn and Haas, Croydon, UK) was added.

Linearity measurements without probe were performed by using $0.25,0.5,0.75,1.0,1.25,2$ and $3 \mathrm{mM}$ $\beta$-D $(+)$ glucose solutions in a Dulbecco's physiological buffer. Whereas, linearity measurements with probe were performed by using 1.4, 2.8, 5.6, 11.1, 16.7, 22.2 and $27.8 \mathrm{mM} \beta-\mathrm{D}(+)$ glucose solutions in a Dulbecco's physiological buffer.

Cellulose acetate ( $53 \%$ acetyl) and polyvinyl acetate of high molecular weight were obtained from Farmitalia Carlo Erba (Milan, Italy). For casting the cellulose membrane, a precision gauge tool (from Precision Gage and Tool Co, Dayton, $\mathrm{OH}$ ) was used. This membrane, with about $100 \mathrm{Da}$ MWCO, was prepared as previously reported (Moscone and Mascini, 1993a,b,c).

\subsection{Procedures}

For in vitro experiments the microdialysis probe was immersed in a beaker containing standard glucose solutions and perfused with a physiological solution. The peristaltic pump drives the carrier solution through the microdialysis probe at constant rate. A steady-state current is obtained. The standard glucose solution, where the microdialysis probe is immersed, was manually changed.

The biosensor's zero current was tested immediately after the electrode assembly, after 2 and $24 \mathrm{~h}$ of monitoring, using the perfusion solution. Only electro-

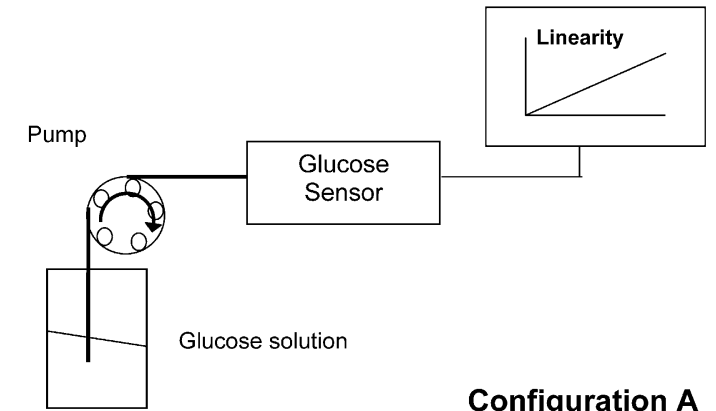

Configuration A

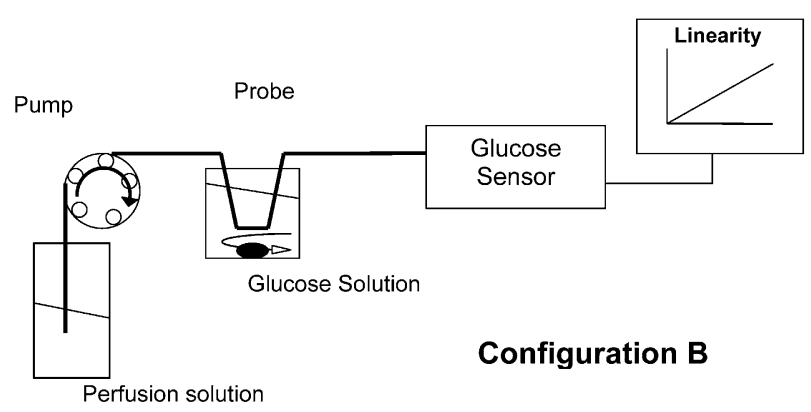

Fig. 2. Configuration A, linearity test without the probe. The instrument directly delivers the glucose solution from the pump to the biosensor. Configuration $\mathrm{B}$, linearity test with the probe along the fluidic line. The instrument collects the glucose solution from the probe, according to the microdialysis principle.

des with a zero current below $1.0 \mathrm{nA}$ were used for the experiments.

On-board, short term and long term stability and zero current of the sensor were checked without the microdialysis fibre.

Linearity tests were performed without probe using linearity solutions, as shown in Fig. 2 (configuration A). When a steady state current was obtained, the glucose solution was replaced with a glucose solution of higher concentration. The instrument was set in order to record results every $3 \mathrm{~s}$ and the pump speed was regulated to $100 \mu 1 / \mathrm{min}$.

Linearity tests were also performed connecting the microdialysis probe along the fluidic line, as shown in Fig. 2 (configuration B). The peristaltic pump drove the perfusion solution at constant rate through the microdialysis probe, which was immersed in standard glucose solutions maintained under stirring. The instrument was set to record the results every $3 \mathrm{~min}$ and the pump speed was regulated to $20 \mu 1 / \mathrm{min}$. A specific programme for PC was used to record the instrument results every second.

In short term stability tests calibration and perfusion solutions were used to check the sensor stability during a 24-48 $\mathrm{h}$ monitoring period. After the zero current tests, the calibration solution was pumped trough the fluidic line. At the end of the experiment the sensor's zero current was checked again. 

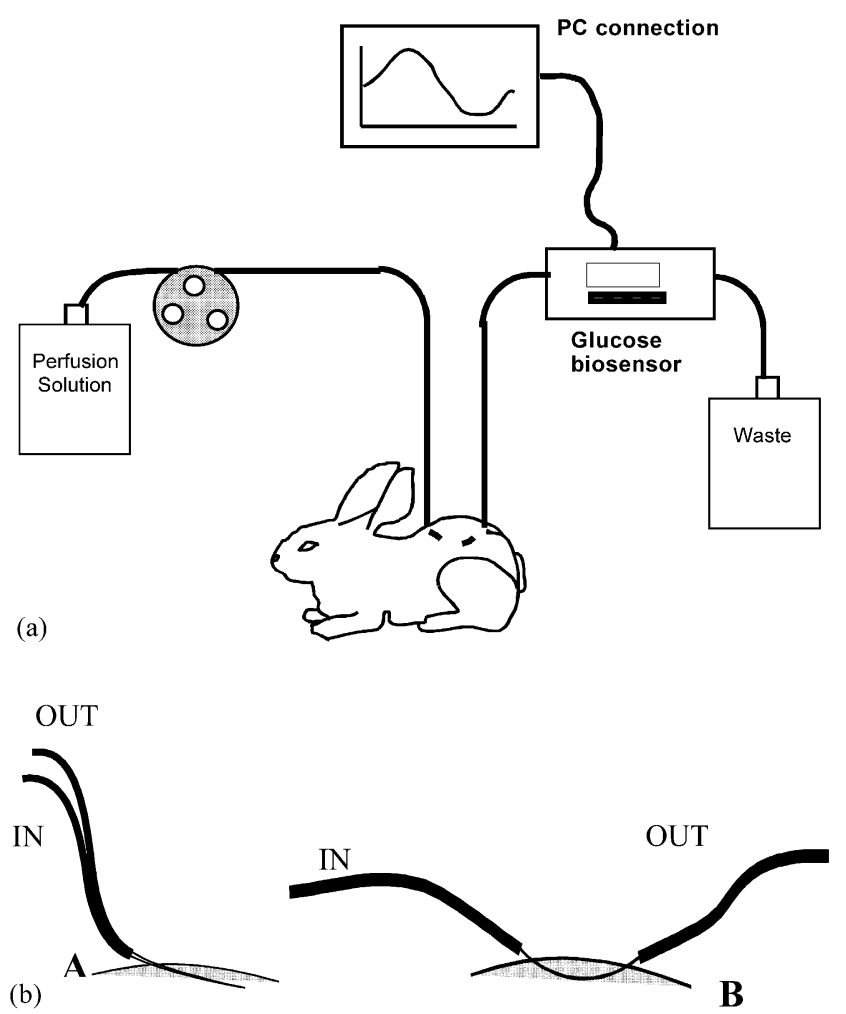

Fig. 3. (A) Configuration of the in vivo experiments with rabbits. A buffer solution is delivered by the peristaltic pump through a microfiber, inserted under the skin. According to the dialysis principle, the glucose is sampled and delivered to the biosensor. The reaction occurs continuously and a proportional current signal is detected and displayed every second. The residual reaction fluid is delivered into a waste bag. (B) A, coaxial mono fiber; B, linear fiber with opposite inlets.

To verify the on-board stability, the biosensor was directly connected to the calibration solution without probe. The zero current was checked before connecting the calibration solution to the biosensor. Then the stable signal of current (within $\pm 0.5 \mathrm{nA}$ ) was recorded, as control current. We checked the on-board stability after $1,6,7,8,9$ and 10 months from the biosensor assembly.

In long-term stability experiments we checked the response of five sensors during a 10 months period. They were maintained at temperatures of $25-29{ }^{\circ} \mathrm{C}$ (room temperature); 37 and $45{ }^{\circ} \mathrm{C}$ in the oven (MICRA) with perfusion solution in stand-by mode. The oven temperatures were checked every day. During the experiments we tested the zero current and the calibration signal with perfusion and calibration solution for each sensor. The experiment time finished when the sensors lost $50 \%$ signal as compare with $T_{0}$. Between checks the sensors were left in stand-by conditions (with the fluidic line closed in loop configuration) with perfusion solution and preservant in circulation.

The reproducibility studies were performed using the instrument configuration A (Fig. 2). A glucose solution $(1 \mathrm{mM})$ was pumped several time directly in the biosensor without the probe. Before each injection we waited until the biosensor current returned below $1 \mathrm{nA}$.

The flow system was checked by in vivo experiments using seven different rabbits (R.T.C., Pomezia, Rome) as shown in Fig. 3A. Two different sterilised microdialysis fibres (two ways and one way) were inserted subcutaneously through the skin. In case of the two ways fibre insertion a $18 \mathrm{G}$ needle provided with a Teflon guide was used, whereas for the one way fibre insertion a specific needle was employed (see Fig. 3B). The fibres were inserted in the back of the animal to avoid involuntary muscle contractions near to the sampling point. This in fact would collapse the subcutaneous fibres. No local anaesthetics were used, neither during the fiber implanting nor during the measurements. The rabbits were conscious, but immobilised in dedicated cage throughout the experiment.

Once the fibers reached the correct position in the Teflon guide and in the connector, the nylon tubes were connected to the instruments and the physiological solution was pumped through the system. After controlling that the solution flew without leaks or obstructions, the Teflon guide and the connectors were removed carefully leaving the microfibers in place. Finally, it was fixed by using surgical tape. This procedure took between 5 and $10 \mathrm{~min}$. The two instruments were then fully activated, pumping the perfusion solution into the microdialysis fibers. They recorded the rabbit's subcutaneous blood glucose values every $3 \mathrm{~min}$. After $60 \mathrm{~min}$, which are normally sufficient for stabilisation of glucose concentration in the perfusion solution, in vivo calibration of the instruments was performed. This was done by testing the venous blood glucose level (checked by CL10, Eurochem) and matching the signal (current value) obtained from the instruments by a linear formula:

$\frac{\left([i]_{0}-B\right)}{[G]_{\mathrm{c}}}=F_{\mathrm{c}} \quad[G]_{n}=\frac{\left([i]_{n}-B\right)}{F_{\mathrm{c}}}$

where $[i]_{\mathrm{c}}$ is the current at the time of calibration, $[G]_{\mathrm{c}}$ is the blood glucose concentration sampled at the time of calibration, $B$ is the background current that we assumed at fixed value of $0.5 \mathrm{nA}$ for all the experiment duration, $[i]_{n}$ is the measured current, $[G]_{n}$ is the calculated glucose concentration.

During the experiments the values of subcutaneous glucose concentrations, sampled by the instrument, were compared four times to blood samples drawn from the rabbit's ear. After the instrument calibration, we imposed a glucose load by infusing a concentrated glucose solution into the rabbits ear vein during $5 \mathrm{~min}$ to emulate hyperglycaemia. After a fast increment, the glucose returned to the basal level in about $2 \mathrm{~h}$. Venous glycemia was evaluated five times for each rabbit: one for calibrating the instrument, the others to compare the 


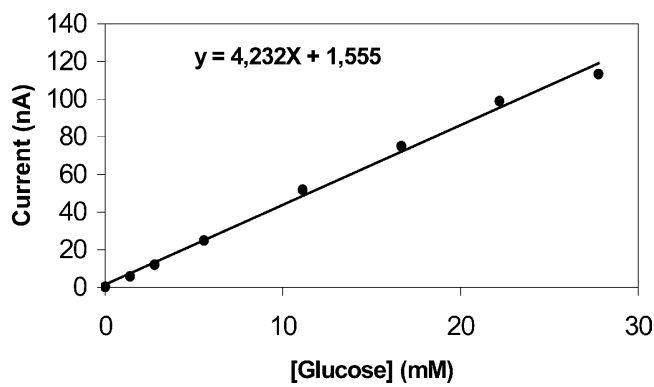

Fig. 4. Linearity test performed using glucose solutions at different concentrations $(1.4,2.8,5.6,11.1,16.7,22.2,27.8 \mathrm{mM})$ in configuration B. Correlation coefficient $R=0.9989$.

instruments values versus a reference method. These glucose control points were collected at basal level, immediately after glucose infusion, $1 \mathrm{~h}$ after the infusion and $2 \mathrm{~h}$ after the infusion.

\section{Results and discussion}

\subsection{In vitro experiments}

Zero current was measured using perfusion solutions. All the electrodes used showed currents below $1 \mathrm{nA}$ (typically $0.5 \mathrm{nA}$ ) after an initial stabilisation period of $24 \mathrm{~h}$. Low current values indicate a very low biosensor noise. For this reason GlucoDay ${ }^{\circledR}$ has a very low detection limit at low levels of glucose concentrations. This is very important in subcutaneous glucose continuous monitoring instruments coupled with microdialysis. In fact, despite the low level of glucose recovery from the dialysis (only 10\%), a good signal can be obtained even using the instrument in the fast flow mode. After checking the zero current, we tested the instruments for the linearity and stability studies.

Linearity tests were performed on ten different biosensors. A typical linearity curve is shown in Fig. 4 , in which the current readings of the biosensor are reported as a function of the glucose concentrations. The insert shows the linear equation with a correlation coefficient $R^{2}$ equal to 0.9964 . In this case, we used glucose concentrations ten times higher than the glucose solutions used without the microdialysis probe, because the percentage of microdialysis was $10 \%$. It can be
Table 2

The sensors stability; the period is expressed in weeks and the current (nA) results recorded by the instruments during the calibration check by using a $0.5 \mathrm{mM}$ glucose solution

\begin{tabular}{lcc}
\hline Instrument s/n & Months & Current (nA) \\
\hline GlucoDay $^{\circledR} 07$ & 0 & 16.8 \\
& 06 & 10.3 \\
& 07 & 11.9 \\
& 08 & 10.6 \\
& 09 & 11.6 \\
GlucoDay $^{\circledR} 12$ & 10 & 10.9 \\
& 0 & 12.0 \\
& 06 & 10.9 \\
& 07 & 10.9 \\
& 08 & 11.7 \\
GlucoDay $^{\circledR} 22$ & 09 & 12.2 \\
& 10 & 13.4 \\
& 0 & 11.2 \\
& 06 & 10.0 \\
& 07 & 9.5 \\
& 08 & 8.6 \\
& 09 & 10.3 \\
& 10 & 11.3 \\
\hline
\end{tabular}

observed that non-linearity occurs at concentrations higher than $27 \mathrm{mM}$. These results well correlate with the ones obtained without the microdialysis probe show a similar linearity with a good correlation coefficient $\left(R^{2}=0.9989\right)$.

The on-board stability results from three different biosensors are reported in Table 1. The current values, shown after several months of weekly use, indicate a very high stability of the biosensor. The biosensor activity and sensitivity is then assured for at least 6 months from the first use.

Long term stability tests (for storage) indicate that the sensors withstand for 4 incubation weeks at $45{ }^{\circ} \mathrm{C}$ and for 11 incubation weeks at $37{ }^{\circ} \mathrm{C}$. At room temperature $\left(25-29{ }^{\circ} \mathrm{C}\right)$ the sensor withstand for a period higher than 32 weeks (Table 2). This extrapolates to a shelf life of more than 2 years at $2-8{ }^{\circ} \mathrm{C}$.

The microdialysed solution reached the biosensor cell from the fiber (subcutaneous tissues) in $53 \mathrm{~s}$, giving the first current signal $11 \mathrm{~s}$ after the solution has arrived to the cell. This means that the system is able to detect any new glucose level from subcutaneous tissue within $1 \mathrm{~min}$ and $8 \mathrm{~s}$.

Table 1

On-board stability of biosensor 1, 6, 7, 8, 910 months after the assembly

\begin{tabular}{|c|c|c|c|c|c|c|c|}
\hline \multirow[t]{2}{*}{ Temperature $\left({ }^{\circ} \mathrm{C}\right)$} & & \multicolumn{6}{|c|}{ Weeks } \\
\hline & & 0 & 3 & 10 & 16 & 24 & 32 \\
\hline $29 \pm 2$ & Sensor C13 & 13.4 & 12.8 & 13.0 & 11.2 & 10.0 & 12.0 \\
\hline $29 \pm 2$ & Sensor C02 & 13.5 & 11.0 & 12.4 & 12.0 & 10.6 & 10.4 \\
\hline $29 \pm 2$ & Sensor C04 & 13.0 & 10.5 & 11.2 & 10.2 & 11.0 & 10.5 \\
\hline
\end{tabular}

Current controlled using a glucose control solution $0.5 \mathrm{mM}$. 


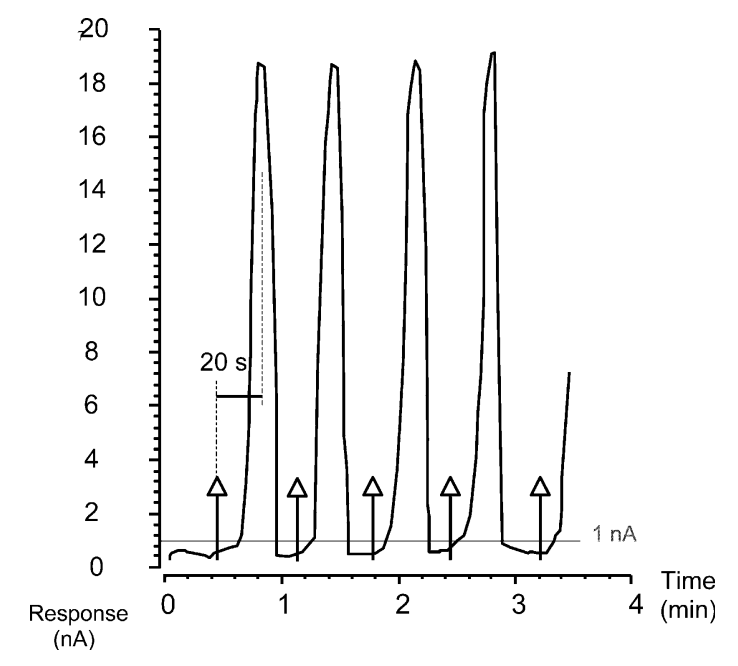

Fig. 5. Reproducibility test: here is shown the biosensor response to four injection of a solution with $1 \mathrm{mM}$ of glucose. The solution was injected directly on biosensor without probe (Fig. 2 configuration A). The background current is under $1 \mathrm{nA}$ and the response time is within $20 \mathrm{~s}$. The arrows indicate the injection point.

The reproducibility study (Fig. 5) shows a good precision when $1 \mathrm{mM}$ glucose solution is directly pumped in the biosensor. We obtained a mean of 18.9 $\mathrm{nA}$ with a S.D. of $0.21 \mathrm{nA}$ and a CV of $1.11 \%(n, 20$ replicates).

\subsection{In vivo experiments}

Both microfiber insertions were well tolerated by the rabbits for the all monitoring period. When the microfibers were removed there was no local infection or irritation.
Fig. 6 shows the glucose profiles of the rabbit \#4, recorded with two instruments and using different probes. The grey line represents the profile obtained with the one-way probe, whereas the black line corresponds to the one obtained with the two-way probe. The calibration and the control glucose points are performed using venous blood, measured with the CL10 (Eurochem) and expressed in mg/dl. Fig. 6 shows experiments made on rabbits where a glucose solution $(500 \mathrm{mg}$ glucose per $\mathrm{kg}$ body weight of the rabbit) was infused into the ear vein for a period of $5 \mathrm{~min}$. Twelve minutes after the start of the infusion, we noticed a variation of the current measured by the instrument connected to the two way microfiber, and after 9 more min the glucose reached the highest level. Twelve minutes after the start of the same infusion, a variation of the current was measured by the instrument connected to the one way microfiber, and after 9-10 more min the glucose signal reached the highest level. The glucose increment reached the basal value in about $2 \mathrm{~h}$ (Ward et al., 1992). We assume a linear relation between the biosensor output (current) and the concentration in the range of interest (one point calibration after $60 \mathrm{~min}$ ). In Fig. 6 are also reported the values of the control points. This shows how the two way fiber system follows in accurate way the blood glucose concentration in rabbits. The sensor response time is fast enough and the stability of the sensitivity acceptable. The overall estimation of the accuracy is reported in Fig. 7. Here, all the rabbit's plasma venous glucose determinations are plotted versus the GlucoDay ${ }^{\circledR}$ glucose values in the Error Grid Analysis form. About $100 \%$ of the 28 points falls in the $\mathrm{A}+\mathrm{B}$ region. Mean bias is $-2.7 \mathrm{mg} / \mathrm{dl}$ and the correlation coefficient is equal to 0.9697 . The percentage

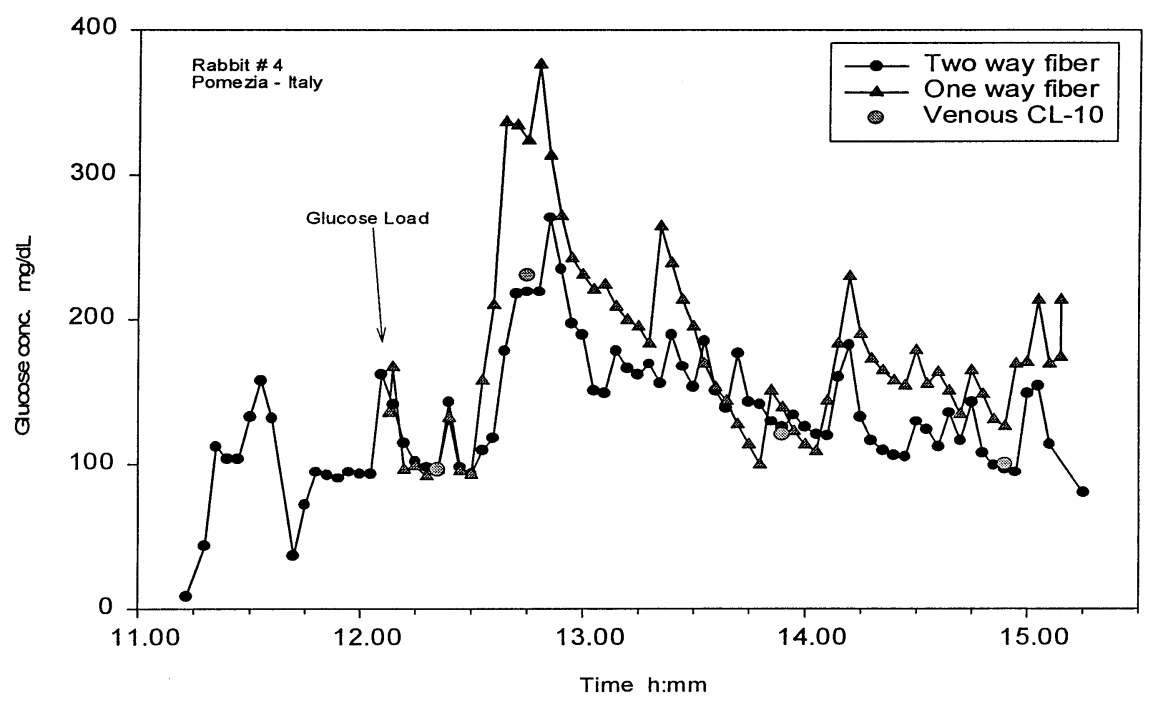

Fig. 6. In vivo monitoring of subcutaneous glucose in the rabbit with two different instrument and different type of microfiber. The grey line represents the glucose profile obtained with one-way probe and the black line obtained with the two-way probe. The calibration point was performed after 60 in of insertion of probes ( $)$ and the glucose control points were performed at basal level, after the glucose infusion, 1 and $2 \mathrm{~h}$ after the glucose load $(\boldsymbol{Q})$ 


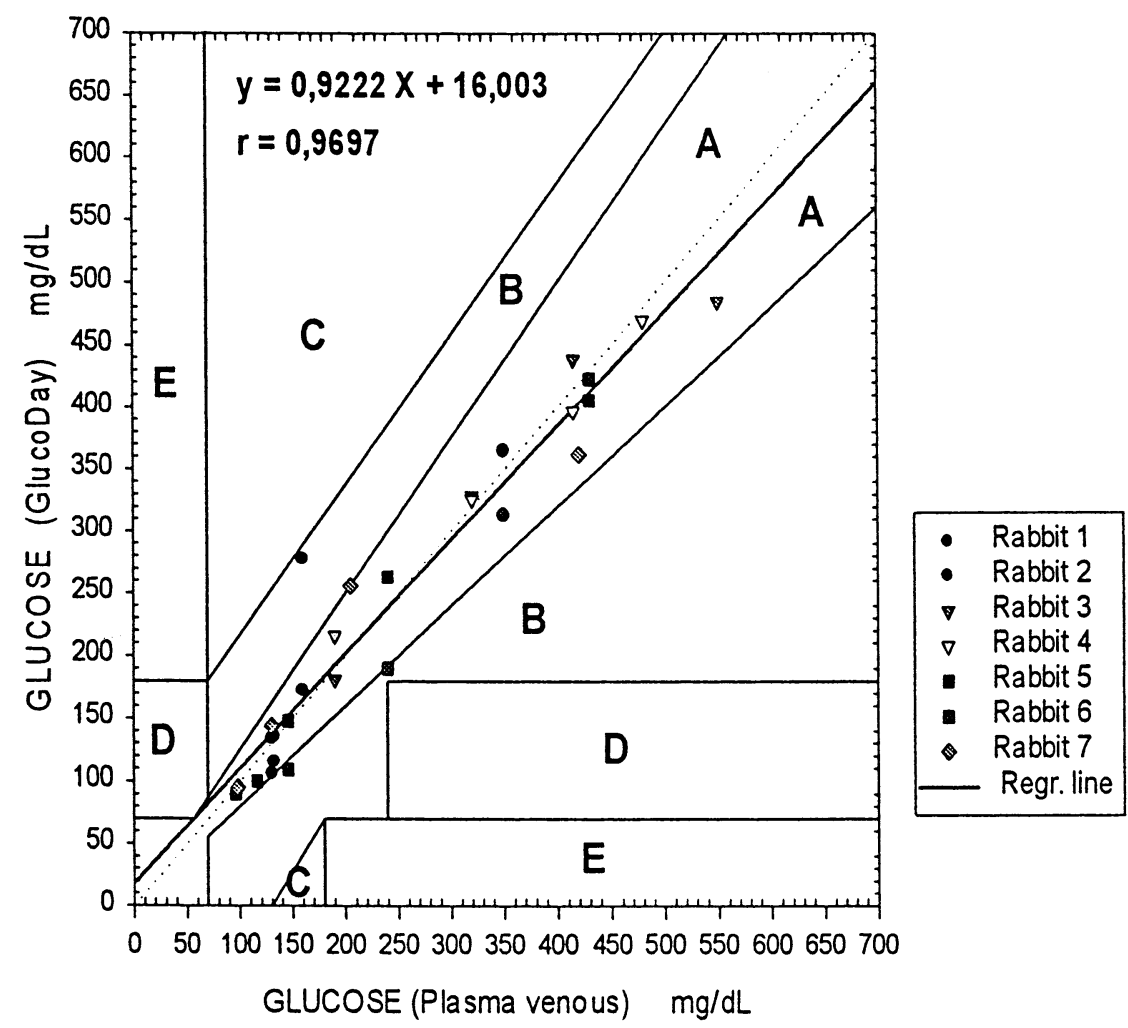

Fig. 7. Error grid analysis with the data coming from seven rabbits. Here are shown the reference venous blood points only (four for each rabbit). All venous data $(n, 28)$ fall in $\mathrm{A}+\mathrm{B}$ zone. The data coming from the instrument with two-way probe only.

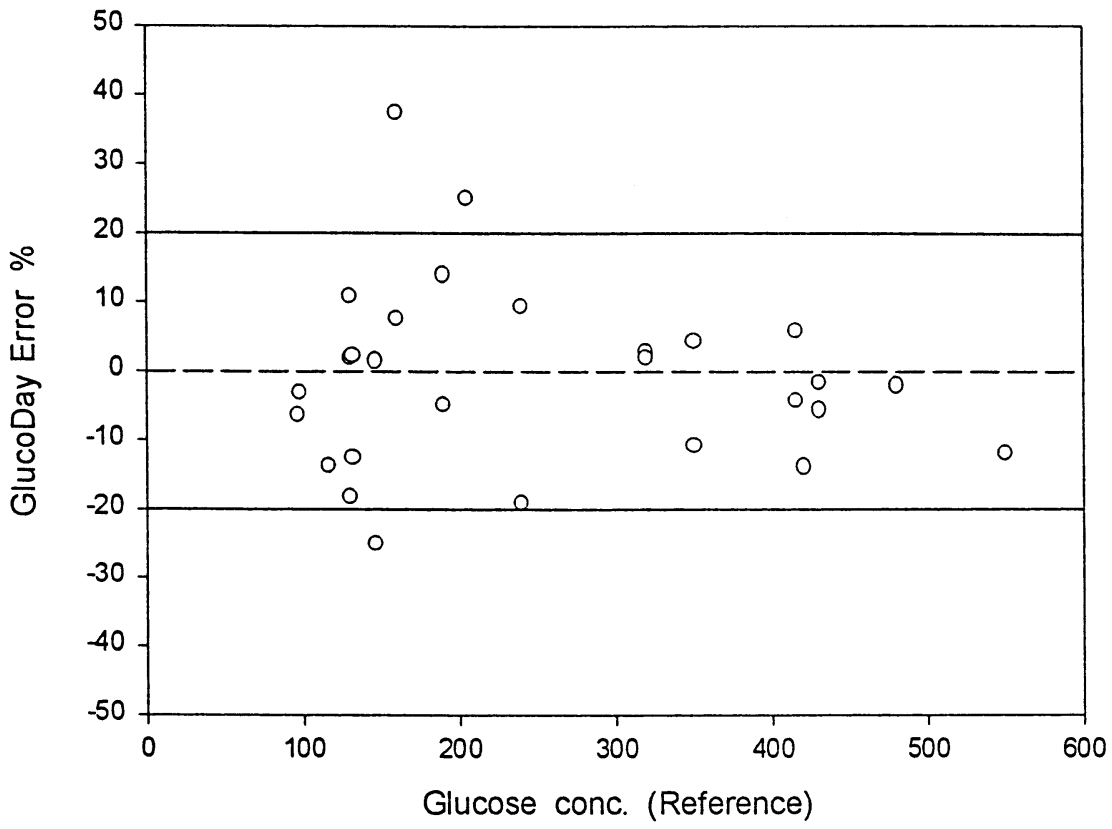

Fig. 8. Scatter plot of GlucoDay ${ }^{\circledR}$ percentage error. About $89.3 \%$ of data give a percentage error within $20 \%$ form the reference (venous blood). No particular error drift are present for all the analytical range.

errors (Fig. 8) is uniform in all the analytical range and the $89.3 \%$ of the data fall within $\pm 20 \%$. The profile in Fig. 6 confirms that the biosensor response time, determined in vitro, is adequate also during fast transient (up to $5 \mathrm{mg} / \mathrm{dl}$ per $\mathrm{min}$ ) of the glucose concentration.

After each puncture for blood collection, the graph in Fig. 6 shows (especially in the two way fiber system) a 
little increments in the glucose level. This phenomenon could be explained considering the release of substances, such as cortisol or adrenaline in a subject under stress conditions. These substances stimulate the liver to grant a glucose release. It is not know the interval of time between the liver stimulation and the substances release (Goldestein et al., 1993). However, considering the insufficient number of points collected (punctures) no final conclusion can be drawn.

\section{Conclusions}

We demonstrated in the past (Moscone and Mascini, 1993b) with a bulky apparatus, the possibility of continuous monitoring of the subcutaneous glucose up to $3 \mathrm{~h}$. Finally, now we have demonstrated the feasibility up to at least $4 \mathrm{~h}$ with a wearable device using the wall jet principle coupled to a microdialysis fiber placed subcutaneously. We demonstrated that this device can detect in appropriate way the subcutaneous glucose concentration in animals. For this reason the analytical and clinical studies of the GlucoDay ${ }^{\circledR}$ system on diabetic patients are now in progress.

\section{References}

Alcock, S.J., Turner, A.P.F., 1996. Prospects for In vivo Sensing. Cranfield Press.

Aussedat, B., Dupire-Angel, M., Gifford, R., et al., 2000. Interstitial glucose concentration and glycemia: implications for continuous subcutaneous glucose monitoring. Am. J. Physiol. Endocrinol. Metabol. 278 (4), E716.

Goldestein, R.E., Wasserman, D.H., McGuinness, O.P., et al., 1993. Effects of chronic elevation in plasma cortisol on hepatic carbohydrate metabolism. Am. J. Physiol. 264, E119-E127.

Hurd, Y.L., Kehr, J., Ungersted, U., 1988. In vivo micro dialysis as a technique to monitor drug transport: correlation of extracellular cocaine levels and dopamine overflow in the rat brain. J. Neurochem. 51, 1314

Kerner, W., Kiwi, T.M., Linke, B., Keck, F., Zier, M., Pfeiffer, E., 1993. The function of a hydrogen peroxide detecting electro- enzymatic glucose electrode is markedly impaired in human subcutaneous tissue and plasma. Biosens. Bioelectron. 8, 473-482.

Mastrototaro, J., 1999. The MiniMed continuous glucose monitoring system (CGMS). J. Pediatr. Endocrinol. Metab. 12 (suppl 3), 751758 .

Moscone, D., Mascini, M., 1993a. Microdialysis coupled with glucose biosensor for subcutaneous monitoring. Analysis 21, M40-M42.

Moscone, D., Mascini, M., 1993b. In: Guilbault, G.G., Mascini, M. (Eds.), In vivo Monitoring with Microdialysis Probe. In Uses of Immobilized Biological Compound. Kluwer Academic Publisher, pp. $115-122$

Moscone, D., Mascini, M., 1993c. Microdialysis and glucose biosensor for in vivo monitoring. Ann. Biol. Clin. 21, M40-M42.

Moscone, D., Pasini, M., Mascini, M., 1992. Subcutaneous microdialysis probe coupled with glucose biosensor for in vivo continuous monitoring. Talanta 39-8, 1039-1044.

Pfeiffer, E.F., Sternberg, F., Meyerhoff, C., Mennel, F.J., Bischof, F., 1995. Subcutaneous glucose concentration in humans. Real estimation and continuous monitoring. Diabetes Care 18 (9), 1266-1269.

Pitzer, K.R., Desai, S., Dunn, T., et al., 2001. Detection of hypoglicemia with the GlucoWatch biographer. Diabetes Care $24,881-885$

Rao, O., Glikfeld, P., Guy, R.M., 1993. Reverse ionophoresis: development of a non invasive approach for glucose monitoring. Pharm. Res. 10, 1751-1755.

Satish, K., Russel, O.P., Neil, R.A., et al., 1999. Correlation of fingerstick blood glucose measurements with GlucoWatch biographer glucose results in young subjects with type 1 diabetes. Diabetes Care 22, 1708-1714.

Scheller, F.W., Pfeiffer, D., Schubert, F., Renneberg, R., Kirstein, D., 1987. In: Turner, A.P.F., Karube, I., Wilson, G.S. (Eds.), In biosensors: Fundamentals and Application. Oxford University Press, pp. 315-1346.

Thome-Duret, V., Reach, G., Gangnerau, M.N., Lemonnier, F., Klein, J.C., Zhang, Y., Hu, Y., Wilson, G.S., 1996. Use of a subcutaneous glucose sensor to detect decreases in glucose concentration prior to observation in blood. Anal. Chem. 68, 38223826

Vadagama, P., Desai, M.A., 1991. In: Blum, L.J., Coulet, P.R. (Eds.), In vivo Biosensors from Biosensors Principles and Applications. Marcel Dekker, New York, pp. 303-338.

Wagner, J.G., Schmidtke, D.W., Quinn, C.P., Fleming, T.F., Bernacky, B., Heller, A., 1998. Continuous amperometric monitoring of glucose in a brittle diabetic chimpanzee with a miniature subcutaneous electrode. Proc. Natl. Acad. Sci. USA 95, 63796382.

Ward, K.J., Haaland, D.M., Robinson, M.R., Eaton, R.P., 1992. Postprandial blood glucose determination by quantitative midinfrared spectroscopy. Appl. Spettrosc. 46, 959-965. 